\title{
'Giant' magnetoresistance in obliquely co-evaporated Co-Ag films
}

\author{
J.C. Lodder, P. de Haan and H. van Kranenburg \\ MESA Research Institute, Information Storage Technology Group, University of Twente, PO Box 217, 7500 AE Enschede, \\ The Netherlands
}

Received 8 March 1993; in revised form 1 June 1993

\begin{abstract}
Magnetoresistance (MR) measurements at room temperature have been performed on obliquely (co-) evaporated $\mathrm{Ag}-\mathrm{Co}$ films deposited at room- and elevated-temperatures. The 'giant' magnetoresistance ratio (max. $13 \%$ for a composition of about $\mathrm{Co}_{35} \mathrm{Ag}_{65}$ ) over a wide range of compositions has been measured. The films are polycrystalline and grown in a columnar morphology. The columnar diameter depends on the thickness and is $<20 \mathrm{~nm}$ at $400 \mathrm{~nm}$ thickness. From XRD, NMR and saturation magnetization $\left(M_{\mathrm{s}}\right)$ vs. at $\% \mathrm{Ag}$, one can conclude that the films consist of $\mathrm{Co}-\mathrm{Co}$ and $\mathrm{Ag}-\mathrm{Ag}$ clusters. The coercivity depends on the thickness of the films $(100-700 \mathrm{~nm})$ and varies from 5 to $15 \mathrm{kA} / \mathrm{m}$.
\end{abstract}

\section{Introduction}

Since Baibich et al. [1] reported in 1988 on the 'giant' magnetoresistance (MR) effect in $\mathrm{Fe} / \mathrm{Cr}$ multilayers, large effects were reported in other multilayer systems consisting of a ferromagnetic component and a conducting non-ferromagnetic component, but also in sandwich structures of, i.e., $\mathrm{FeMn} / \mathrm{NiFe} / \mathrm{Cu} / \mathrm{NiFe}[2,3]$, and very recently also large effects have been discovered in so-called granular thin films [2-5] prepared by co-sputtering of ferromagnetic materials $(\mathrm{Co}, \mathrm{Fe}$, $\mathrm{Ni}, \mathrm{NiFe}$ ) and the non-ferromagnetic materials $\mathrm{Ag}$ and $\mathrm{Cu}$.

These large magnetoresistance effects can be very interesting for sensor applications if the properties of the layers can be adjusted to what is needed. In granular films, one parameter affecting the magnetoresistance is the size of the ferromagnetic granules. The aim of this study is to show an alternative method, instead of sputtering from composite targets, to obtain small ferromagnetic clusters in a non-ferromagnetic matrix. The

Correspondence to: J.C. Lodder, MESA Research Institute, Information Storage Technology Group, University of Twente, PO Box 217, 7500 AE Enschede, The Netherlands. granularity of the sputtered films is based on the fact that the solubility of the ferromagnetic materials in the conducting material ( $\mathrm{Ag}$ or $\mathrm{Cu}$ ) is very small, allowing the formation of metastable alloys. A post-annealing treatment (at higher temperature) on these sputtered films leads to a diffusion process and consequently to a further precipitation of $\mathrm{Co}$ in the $\mathrm{Ag}$ or $\mathrm{Cu}$ matrix.

We introduce the oblique incidence vapour flux deposition method using opposing directions for the ferromagnetic and non-ferromagnetic materials by which the compositional separation of both materials is enhanced by the process itself.

Here we report about the preliminary results on composition, microstructure, magnetic properties and GMR values of oblique co-evaporated films of $\mathrm{Co} / \mathrm{Ag}$.

\section{Preparation technique}

A Leybold high vacuum system LH560 was used for co-deposition of $\mathrm{Co}$ and $\mathrm{Ag}$ under an angle using two e-beam guns. The two vapour beams arrive from opposite directions under the same angle. The basic geometry of the process is illustrated in Fig. 1. 


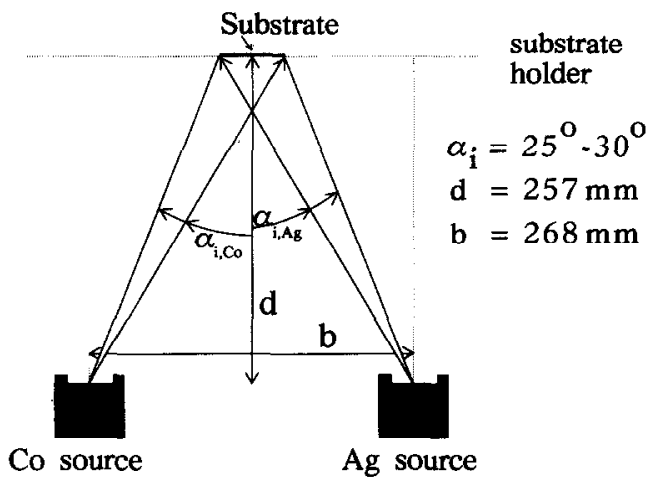

Fig. 1. Basic geometry of the evaporation process. For the samples discussed in this paper, the substrate was located in the evaporation plane in between the two sources.

The two e-beam sources are situated $268 \mathrm{~mm}$ from each other. The distance between source and substrate holder is $257 \mathrm{~mm}$. The incoming angle for both materials is equal $\left(\alpha_{\mathrm{i} 1}=\alpha_{\mathrm{i} 2}=\right.$ $27.5^{\circ}$ ). The angle of incidence is defined between the film normal and vapour flux direction. The substrate material used is $\mathrm{Si}(\mathbf{1 0 0})$ and the deposition temperature was either ambient (room) temperature (referred to as $T_{\mathrm{r}}$ samples) or high (referred to as $T_{\mathrm{h}}$ samples). In the latter case, the temperature near the heater was $400^{\circ} \mathrm{C}$. The substrate temperature, measured by means of a thermocouple in contact with the back of the $\mathrm{Si}$ substrates, was lower than this heater temperature. The lowest back pressure in the turbo pumped system was about $10^{-7}$ mbar.

The total deposition rate $(\mathrm{Co}+\mathrm{Ag})$ was varied between 3.5 and $12.8 \AA / \mathrm{s}$. The separate deposition rates of both sources during deposition were monitored by calibrated quartz crystal oscillators. The thickness of the layers was between 81 and $706 \mathrm{~nm}$. The deposition rates of $\mathrm{Co}$ and $\mathrm{Ag}$ were, respectively, $1.4-4.2$. $\mathrm{\AA} / \mathrm{s}$ and $0.8-7.6 \AA / \mathrm{s}$. As source materials, we used $99.99 \%$ purity $C o$ and $\mathrm{Ag}$. The composition of the films varied between 34.9 and 84.2 at\% Co.

With the substrates in the middle position (see Fig. 1) between the two sources, the two vapour fluxes overlap each other. Since the two separate directions are intended to arrive at the growing film surface from opposite directions, it is important that this overlapping does not have too much effect on the vapour impingement. In the experimental situation, the background pressure was sufficiently low and caused no significant deterioration of the vapour flux direction.

For various types of material, the two separate sources of vapour flux can yield a special type of compositional separation (CS), the so-called process-induced compositional separation, which is closely related to the evaporation geometry.

The use of this technology for compositional separated films has been proved by using this method for preparing $\mathrm{Co}-\mathrm{Cr}$ films not only for perpendicular magnetic recording [6-8] but also for other applications $[9,10]$. The results presented in this paper are based on a systematic research on obliquely (co-)evaporated $\mathrm{Co}-\mathrm{Cr}$ media for magnetic recording applications. The relations between deposition parameters, morphology, texture and magnetic behaviour of this type of thin film have been studied in our group in the past 5 years $[6-8,11,12,17,19]$. From this study we learned, from experimental data obtained by various methods and techniques, that in the case of $\mathrm{Co}-\mathrm{Cr}$ even at ambient temperature a compositional separation takes place. In the case of evaporation, the film temperature is much lower than the ambient sputter temperature due to the difference of particle energies. In both cases, deposition at an elevated temperature or an annealing step after deposition can give a more pronounced compositional separation.

The data obtained from $\mathrm{Co}-\mathrm{Cr}$ was the inspiration to try also $\mathrm{Co}-\mathrm{Ag}$ because it is known that these materials will hardly form an alloy. This fact in combination with the deposition technology at ambient temperature should give us probably a more separated $\mathrm{Co}$ and $\mathrm{Ag}$ phase. This is of course also dependent on the angle of incidence and the proportion of Co to $\mathrm{Ag}$. So we expected to tailor the local chemical composition in the case of $\mathrm{Co}-\mathrm{Ag}$ in a better way than in the case of $\mathrm{Co}-\mathrm{Cr}$. Last but not least we found by NMR experiments [16] that compositional separation has occurred in $\mathrm{Co}_{42} \mathrm{Ag}_{58}$ films. After annealing at successive steps of 225,325 and $425^{\circ} \mathrm{C}$, each for $2.5 \mathrm{~h}$, the compositionally separated state developed even more; in the NMR spectrum only the pure Co component was present. 
Magnetic properties have been determined by VSM and torque magnetometer while the MR measurements were carried out by a four-point in-line probe with both voltage and current (of 1 $\mathrm{mA}$ ) in plane of the film. Structural and compositional analysis have been carried out using XRF, XRD and SEM. All measurements have been carried out at room temperature.

\section{Driving forces of compositional separation (CS)}

Compositional separation in Co-Ag films effectively means chemical non-homogeneous distribution of $\mathrm{Co}$ and $\mathrm{Ag}$ in the lateral direction. It considerably influences the magnetic behaviour of the films and it is therefore one of the most important structural feafures. Unfortunately, it is also a difficult phenomenon to characterize, mainly because of the small dimensions of the final morphology of the deposited layers (see below).

Two very useful and clear distinctions can be made to understand the mechanism of $\mathrm{CS}$, namely:

(1) there is a driving force related to the process geometry of the two opposite vapour flux directions of the two materials used [11,12] in our case $\mathrm{Co}$ and $\mathrm{Ag}$;

(2) there are driving forces related to the deposition temperature which can be defined as thermally enhanced CS, which are not restricted to the technology used in this work. One can find this mechanism also for sputtered, evaporated and electroplated plated thin films.

Hereafter some more attention will be given to the ideas behind the process-induced CS. An ideal representation of the process is given in Fig. 2.

The geometric effect is due to the shadowing mechanism [13] because the $\mathrm{Co}$ and $\mathrm{Ag}$ atoms have shadowed areas that are positioned opposite to each other. The most likely impingement place for $\mathrm{Ag}$ is, at every stage of film growth, in the shadowed area of the Co vapour and especially on one side of the tilted columns and in case of a high percentage of $\mathrm{Ag}$, and vice versa. The amount of tilting of the columns and the related

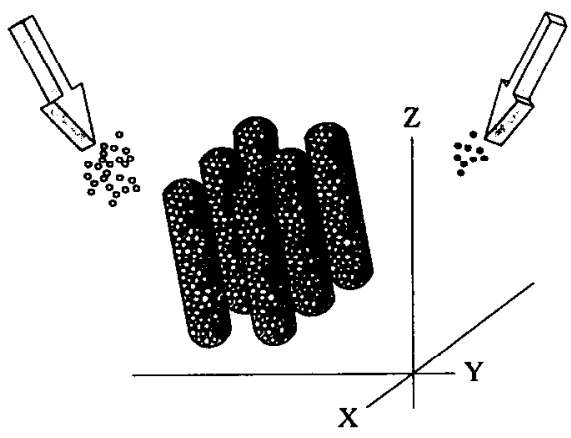

Fig. 2. A 3D model of the process-induced compositional separation [16].

oblique top of the columns count significantly in this matter. If the adatoms have limited mobility (at low temperature) then they will stick at a position very near to the initial impingement place. This can lead to the process-induced CS, where one side of the columns is Ag-rich. In order to have such a geometrical effect, it is essential that the two vapour beams are really coming from separate directions and that no mixture of directions is formed in the overlapping part of the flux. Also the background pressure is important, because a residual gas will interfere with the vapour flux and make its direction less distinct.

To see whether two metals will form an alloy, the 'hcat of formation', which is formulated in the Miedema model [14], can be used as an indicator. When the heat of formation is negative, energy is freed upon alloying. Miedema's calculations resulted in a fast graphical method (alloying diagram) to see if two metals will alloy or not. It appeared that $\mathrm{Co}$ will not alloy with $\mathrm{Ag}$ (and $\mathrm{Cu}$ and $\mathrm{Au}$ ).

This fact and the deposition technology used can give us separated $\mathrm{Co}$-(rich) and $\mathrm{Ag}$-(rich) areas.

\section{Structure and morphology}

Two of the thickest samples (700 and $400 \mathrm{~nm}$ ) containing 55 and 59 at\% Ag were examined with SEM in cross-section parallel to the evaporation plane (see Fig. 3). 

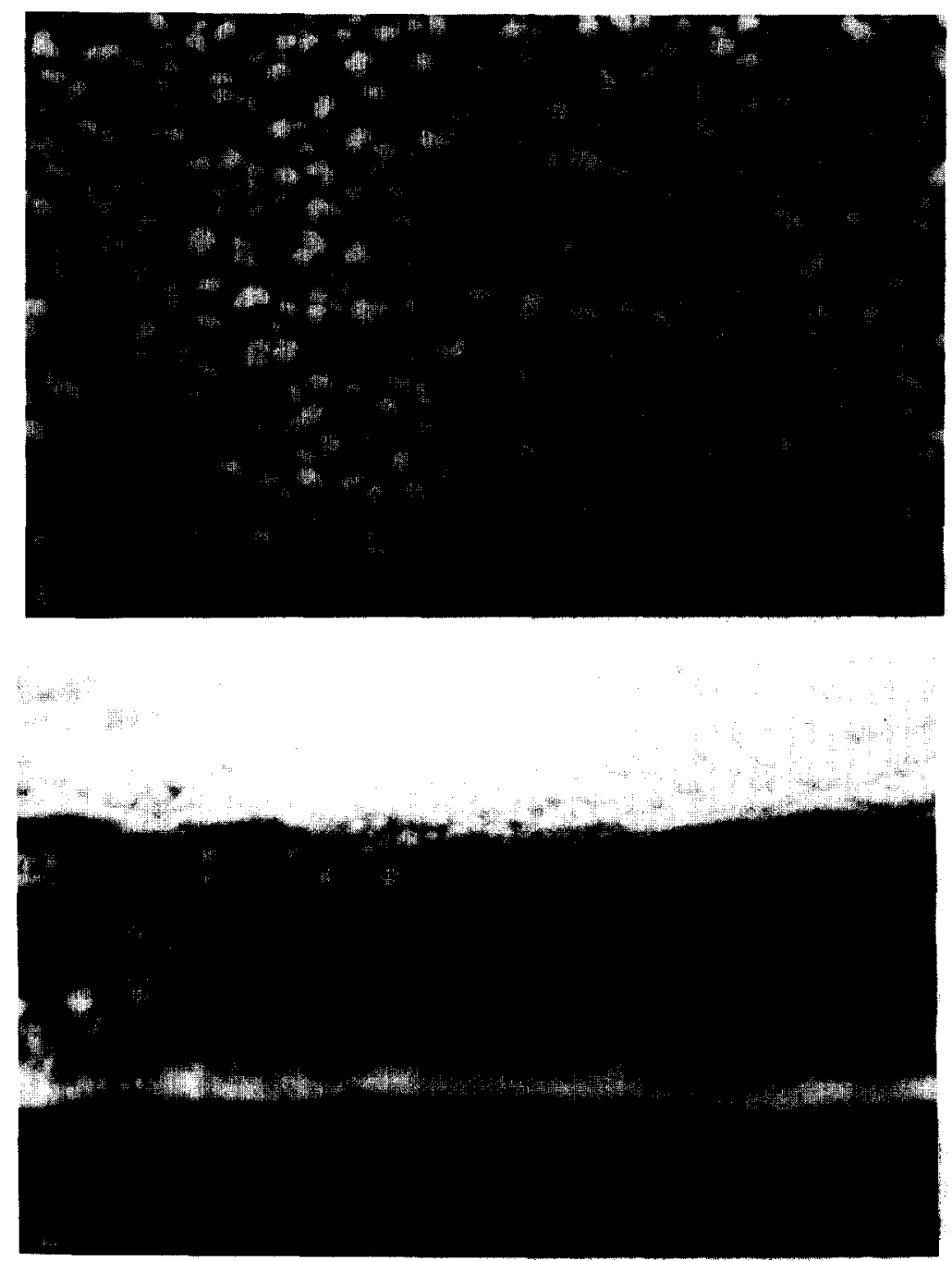

Fig. 3. (a) A fractional cross-section // evaporation plane of a Co-Ag film by SEM; (b) SEM surface observation of a Co-Ag film (tilt angle in the SEM $30^{\circ}$ ).

A columnar structure is present and tilted about $10^{\circ}$ towards the $\mathrm{Ag}$ source direction. This is obviously the result of the higher at\% $\mathrm{Ag}$ than at $\% \mathrm{Co}$ in the film. The columnar size is very small (for instance much smaller than $\mathrm{Co}-\mathrm{Cr}$ samples made under the same conditions), namely $<20 \mathrm{~nm}$ for $400 \mathrm{~nm}$ and $<30 \mathrm{~nm}$ for $700 \mathrm{~nm}$ thick layers. From many studies in the literature, it is known that, in the case of sputtering and evaporation, materials tend to grow in a columnar shape. In the case of oblique evaporation, the columnar growth is mainly promoted by the shadowing mechanism. Depending on the substrate conditions, one can find that a columnar diameter grows as a function of the thickness of the layer. In the case of $\mathrm{Co}-\mathrm{X}$ compositions $\mathrm{X}=\mathrm{Cr}$, $\mathrm{Ta}, \mathrm{Ag}$ ), we found this effect during sputtering and evaporation. By using a seed layer, this effect is drastically reduced and in certain combinations the columnar diameter can be determined as constant over the layer thickness. Influences from bias, sputtergas and substrate temperature can be 
clearly seen. The nucleation and growth process is responsible for the final growth of the layer. The columnar diameters $(d)$ as a function of the layer thickness $(t)$ of Co-Ag films are: $t=100$ $\mathrm{nm}, d=7.5-15 \mathrm{~nm} ; t=250 \mathrm{~nm}, d=12.5-25 \mathrm{~nm}$; $t=>400 \mathrm{~nm}, d=15-35 \mathrm{~nm}$. For higher substrate temperature (about $250^{\circ} \mathrm{C}$ ), we found: $t=$ $250 \mathrm{~nm}, d=12.5-30 \mathrm{~nm} ; t=400 \mathrm{~nm}, d=15-50$ $\mathrm{nm} ; t=750 \mathrm{~nm}, d=15-110 \mathrm{~nm}$. Compared with sputtered Co-Cr films, the columnar diameter is rather small (for instance $t=600-700 \mathrm{~nm}, d=$ $100 \mathrm{~nm}$ ). The difference is mainly attributed to the higher surface temperature during the growth of the film.

Although there is an increase in columnar diameter with increasing film thickness in the oblique-evaporated $\mathrm{Co}-\mathrm{Ag}$ films, it is much smaller than in the case of sputtered layers and layers evaporated at higher substrate temperature. It can be explained qualitatively by two facts, namely the small increase of layer temperature during growth, and the deposition time for the $700 \mathrm{~nm}$ thick layer is about two times more that for the $400 \mathrm{~nm}$ layer (about $140 \mathrm{~s}$ instead of $80 \mathrm{~s})$. During this deposition traject, the substrate temperature is still increasing and this can have an influence on the columnar diameter growth.

Furthermore, the texture of the layers is strongly (111) oriented. In the fcc case, this is the most favourable crystal plane and in terms of the 'survival of the fastest' growing mode this can cause an increase of the diameter.

Surface SEM observations however revealed larger particles on the surfaces. This surface topology does not seem to consist of columnar tops; instead it is likely to consist of oxidized or sulphide particles, and $\mathrm{Ag}$ compounds are known to form easily. A simple observation of a fresh deposited sample and a two month old sample shows that the latter had a larger amount of the larger and protruding particles. Further analysis. of the morphology and chemical (surface) composition will be carried out.

From XRD measurements, we can conclude that the $\mathrm{Co}-\mathrm{Ag}$ films are polycrystalline and consist of two separate lattices. The Ag sub-lattice is fcc and the Co lattice is either hcp (13-16 at\% $\mathrm{Ag})$ or $\mathrm{fcc}(>31 \mathrm{at} \% \mathrm{Ag})$.

The hcp structure of the lower at\% Ag samples have the lattice data of $d_{002}=2.036-2.040$ $\AA, a=2.495-2.503 \AA$ and $c / a=1.630-1.632$. Furthermore, the (111) Ag lattice spacing is around $2.32-2.34 \AA$ and also a reflection probably from $\mathrm{Ag}_{2} \mathrm{~S}_{2} \mathrm{O}_{7}$ was measured.

For the $>31$ at\% $\mathrm{Ag}$, a separate fcc Co and fcc Ag lattice have been measured. Both lattices have their (111) planes parallel to the film surface and consequently have a texture axis, being [111]

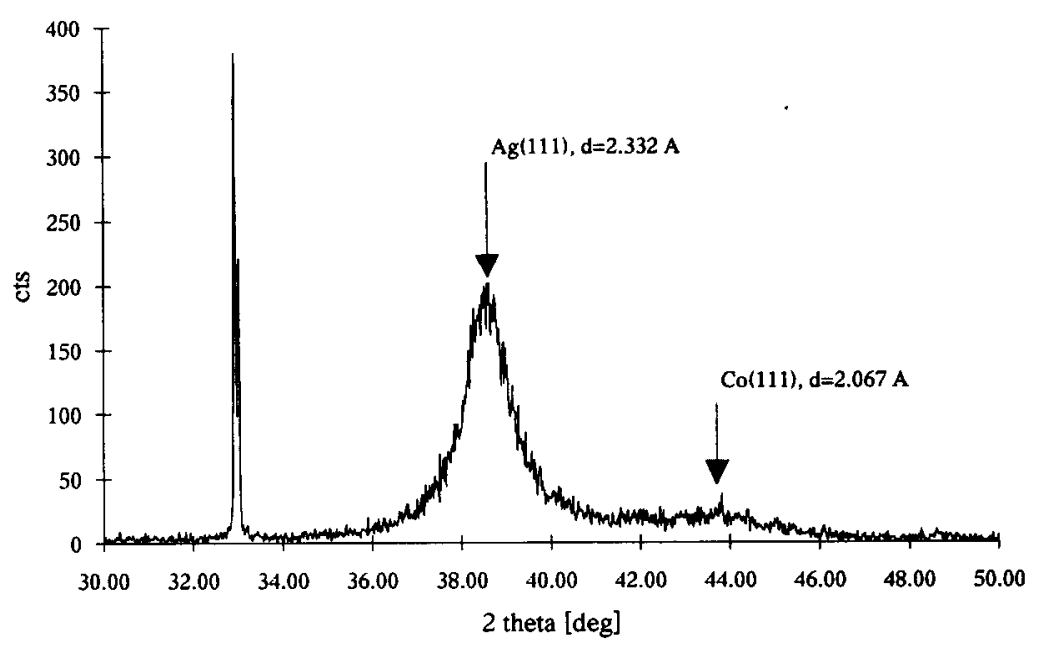

Fig. 4. An XRD scan showing two seperate peaks for $\mathrm{Ag}$ and $\mathrm{Co}$ both from fcc (111) planes. The peak at $2 \theta=33^{\circ}$ is from the Si substrate. 
perpendicular to the surface. The Co(111) lattice spacing is larger than for pure fcc $\mathrm{Co}$ and it increased with $\mathrm{Ag}$ content and decreased with deposition temperature. Measured values are: $2.058 \AA$ (35 at $\%$ and room temperature $\left(T_{\mathrm{r}}\right)$ deposited), 2.058-2.076 $\AA$ (50-60 at\%, $T_{\mathrm{r}}$ ) (see Fig. 4) and $2.054 \AA$ (61 at\%, high temperature). Furthermore, the (111) Ag lattice spacing is smaller (2.332-2.338 $\AA$ at $T_{\mathrm{r}}$ ) than for pure fcc $\mathrm{Ag}(2.539$ $\AA$ ). It increased at higher deposition temperatures $(2.344 \AA)$. The XRD pattern agrees well with the sputtered $\mathrm{Co}-\mathrm{Ag}$ film at a substrate temperature of $100^{\circ} \mathrm{C}$ of Liou et al. [18].

The $\Delta \theta_{50}$ of the $\operatorname{Co}(111)$ is about $16^{\circ}$ and for the $\mathrm{Ag}(111)$ about $19^{\circ}$. After an annealing step of 225,325 and $425^{\circ} \mathrm{C}$ (each step $2.5 \mathrm{~h}$ at $10^{-4} \mathrm{~Pa}$ ), the higher Ag content samples changed from fcc into a mixture of hcp $\mathrm{Co}$ and fcc $\mathrm{Ag}$.

\section{Magnetic analysis}

The magnetoresistance as a function of the film composition is given in Fig. 5. The resistance of the film is measured to a maximum field of 960 $\mathrm{kA} / \mathrm{m}$. The films were not saturated at this field. A typical curve is shown in Fig. 6. The MR is calculated as the difference of $R$ at zero field and maximum field divided by the $R$ at zero field
$\left(\left(R_{0}-R_{\max }\right) / R_{0} \times 100 \%\right)$. Although there is a large variation in the thicknesses of the films, it seems that this has not much effect on the MR. The MR is measured in three directions:

(i) current parallel to the transversal plane, that means perpendicular to the plane of incidence (TM direction) and the magnetic field in plane;

(ii) current parallel to the incidence plane (LM direction) and the magnetic field in plane;

(iii) current in the LM direction and the magnetic field perpendicular to the film plane.

There is not much difference in the measured values; the resistance in the LM direction seems to be a bit larger than found in the TM direction, probably due to the open regions between the columns caused by the shadowing effect in that direction in the film.

Although we did not measure a maximum due to lack of films in the lower Co region, it seems that the curve we find compares quite well with what is found for sputtered films (in the same thickness range) by Barnard et al. [2] although the position of the maximum in our films seems to coincide with the position found for the thicker (also sputtered) films made by the same group [15]. Films deposited at a higher substrate temperature gave a higher value for the MR as films deposited at room temperature, probably due to

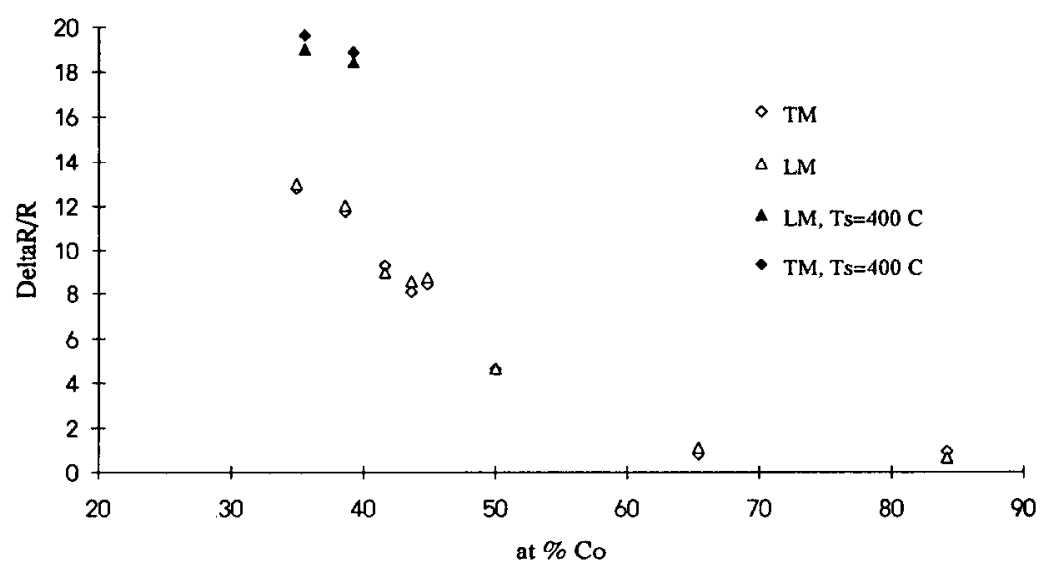

Fig. 5. The magnetoresistance $(\Delta R / R)$ as a function of the Co concentration. 


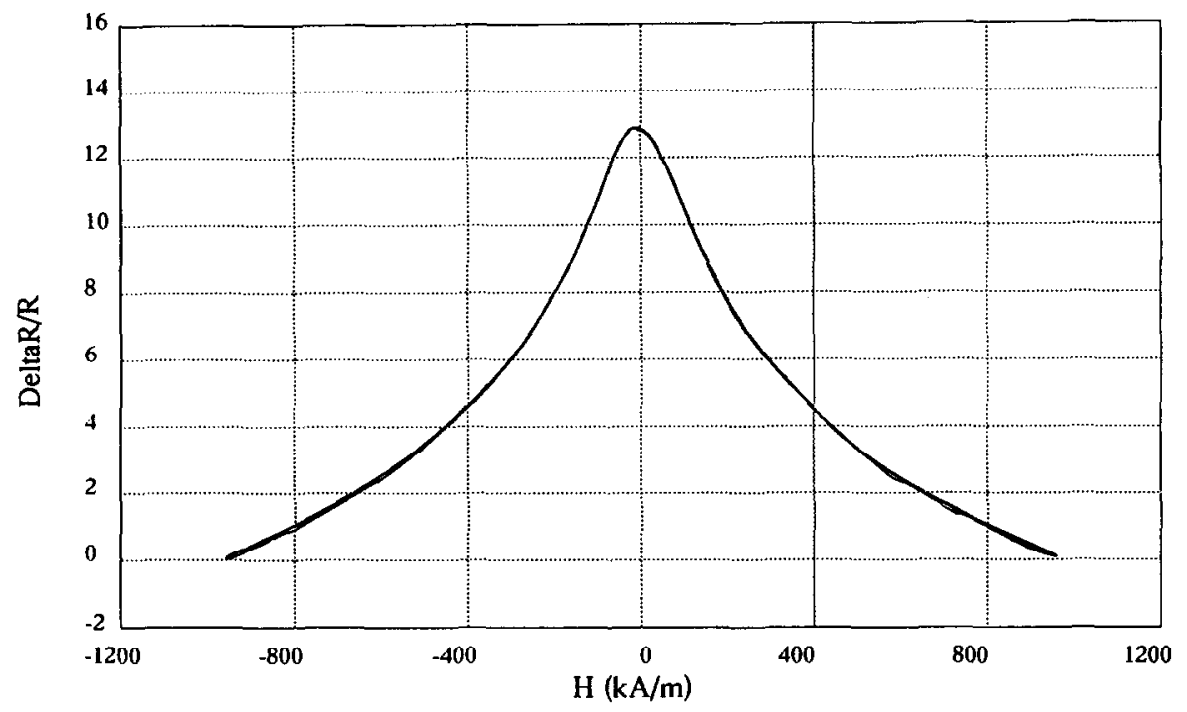

Fig. 6. A typical magnetoresistance curve of a $\mathrm{Co}-\mathrm{Ag}$ film around the optimal content of Co.

the higher mobility of the atoms which will cause a better separation of the $\mathrm{Co}$ and $\mathrm{Ag}$.

Due to the evaporation geometry and the growth mechanism we obtained a different morphology for the different in-plane directions in the film. In the incidence (LM) plane, the columns are separated by open regions due to the shadowing effect. In the plane perpendicular to the incidence plane (TM), where the vapour supply is homogeneous and the shadowing effect is not present, clustering of columns (bundling) can occur under certain deposition conditions. Magnetically this structural difference shows only in a difference in coercivity for the LM en TM planes. In Fig. 7, VSM hysteresis loops measured in the LM direction are shown, which compare very well with the loops measured in the TM direction, except that the $H_{\mathrm{c}}$ is higher in the $\mathrm{LM}$ direction for the in-plane loops (Fig. 8).

In Fig. 8 the coercivity measured in the LM and the TM direction is given as a function of the film thickness. In general the coercivities measured in plane (both LM and TM direction) and perpendicular to the film surface have very low values: for a $200 \mathrm{~nm}$ thick film about $10 \mathrm{kA} / \mathrm{m}$ with a slight dependence on the composition. It can be concluded that the films are more or less isotropic. The slightly higher $H_{\mathrm{c}}$ for thicker films can probably be related to the larger columns.

In Fig. 9, the saturation magnetization $\left(M_{\mathrm{s}}\right)$ is shown as a function of the average at $\% \mathrm{Ag}$. As can be seen, the $M_{\mathrm{s}}$ decreases almost linearly with increasing $\mathrm{Ag}$ content. In order to exclude a mere dilution effect, a correction is made for non-magnetic volume under the assumption of complete separation of $\mathrm{Co}$ and $\mathrm{Ag}$. The calculated $M_{\mathrm{s}}^{*}$ is also given in Fig. 9.

With a non-homogeneous distribution of $\mathrm{Co}$ and $\mathrm{Ag}$, a deviating relation between $M_{\mathrm{s}}$ and the average content of $\mathrm{Ag}$ occurs. The Co volume can be calculated in two different ways. First by using the densities and second by taking the atomic radii. Both methods give within $1 \%$ the same result. Here the atomic radii are used. If in our films $\mathrm{Co}$ and $\mathrm{Ag}$ are assumed to be completely separated, the resulting ferromagnetic film volume $\left(V^{*}\right)$ is related to the total volume $(V)$ through

$V^{*} / V=A /(A+B)$

with $A=4 / 3 \pi r_{C o}^{3} \mathrm{~N}_{\mathrm{Co}}$ and $B=4 / 3 \pi r_{\mathrm{Ag}}^{3} \mathrm{~N}_{\mathrm{Ag}}$.

In this expression the radii of the atoms are denoted as $r$ and the number of atoms as $N$, both with subscripts for $\mathrm{Co}$ and $\mathrm{Ag}$. The $M_{\mathrm{s}}$ 


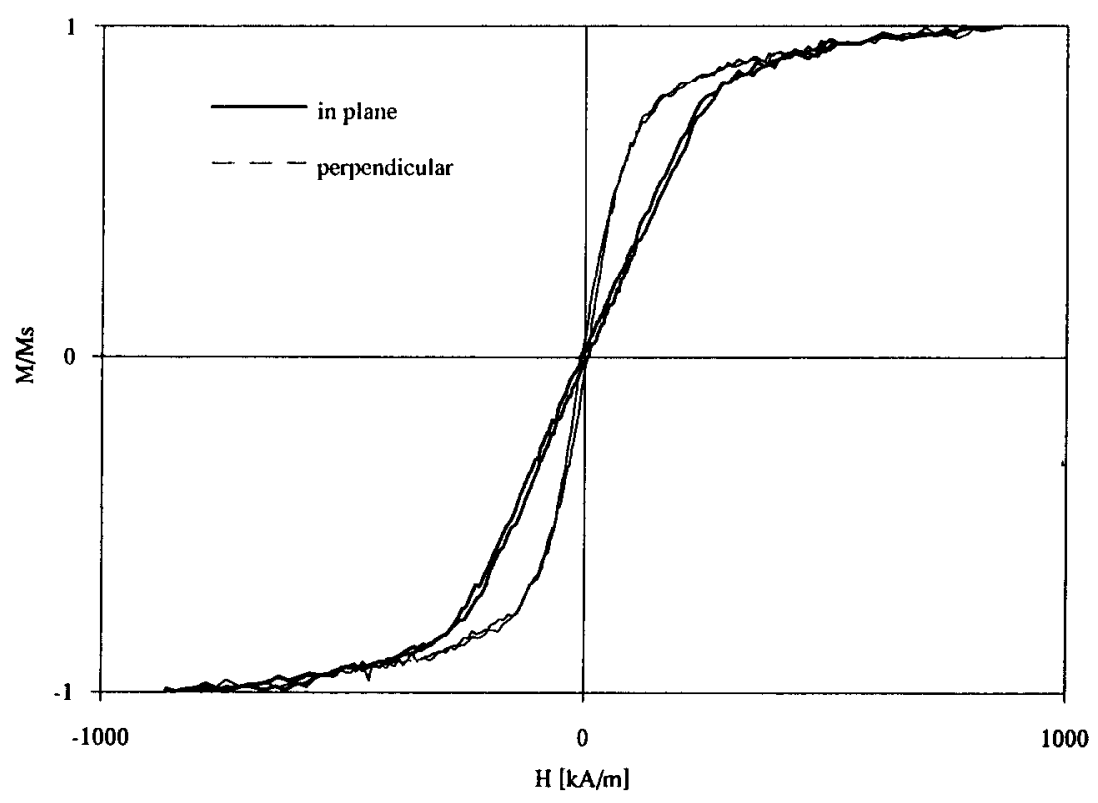

Fig. 7. A typical hysteresis loop of a $\mathrm{Co}-\mathrm{Ag}$ film around the optimal content of $\mathrm{Co}$.

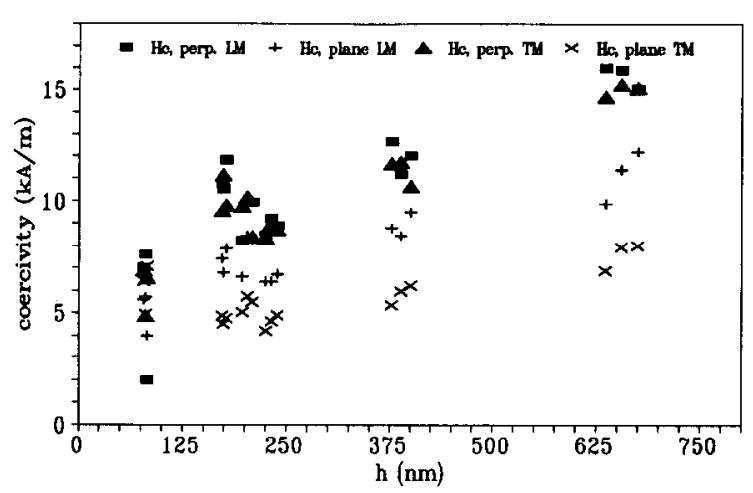

Fig. 8. The coercivity measured in the LM and TM directions, perpendicular to and parallel to the plane, as a function of the film thickness.

under complete separation conditions, $M_{\mathrm{s}}^{*}$ can then be calculated by

$$
\begin{aligned}
M_{\mathrm{s}}^{*} & =M_{s} V / V^{*} \\
& =M_{s}\left(1+\text { at } \% \text { Ag } r_{\mathrm{Ag}}^{3} / \text { at } \% \text { Co } r_{\mathrm{Co}}^{3}\right) .
\end{aligned}
$$

Here $M_{\mathrm{s}}$ is the saturation magnetization if the total film volume would be ferromagnetic. Effectively this comes down to excluding the dilution effect (in clusters) that $\mathbf{A g}$ is supposed to have on

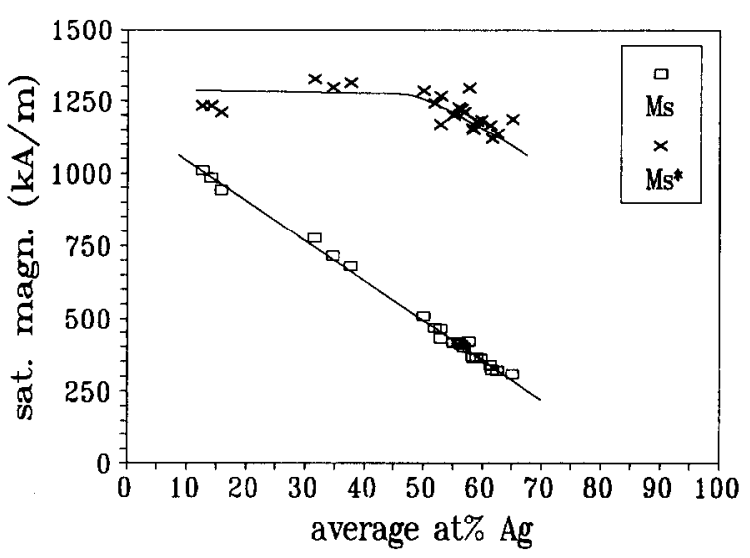

Fig. 9. Saturation magnetizations as a function of the average Ag content [16].

Co. If the films consist of Co clusters on one side and $\mathrm{Ag}$ on the other side of the columns, then this dilution is merely a volume effect and $M_{\mathrm{s}}^{*}(\mathrm{at} \% \mathrm{Ag})$ should be constant. If $\mathrm{Ag}$ is to some extent also present within the Co matrix, then besides the volume effect it also reduces the number of $\mathrm{Co}-\mathrm{Co}$ neighbours. The exchange energy between neighbouring atoms and the Curie temperature of the film are hereby reduced. 
In that case $M_{\mathrm{s}}(\mathrm{at} \% \mathrm{Ag})$ decreases more strongly than in the case of separation into merely clusters and $M_{\mathrm{s}}^{*}(\mathrm{at} \% \mathrm{Ag})$ remains a decreasing function.

At low $\mathrm{Ag}$ content, the calculated saturation magnetization $\left(M_{\mathrm{s}}\right)$ is almost constant with an increasing amount of $\mathrm{Ag}$. This indicates that, at low $\mathrm{Ag}$ compositions, $M_{\mathrm{s}}(\mathrm{Ag})$ is dominantly decreased by mere dilution effect of $\mathrm{Ag}-\mathrm{Ag}$ clusters. The fact that the extrapolated value of $M_{\mathrm{s}}$ is not yet zero at 80 at\% $\mathrm{Ag}$ (and thus not only a decrease of exchange moment occurs due to fewer Co-Co neighbours) supports this. Thus, Co and $\mathrm{Ag}$ have been separated and compositional separation occurred in those samples co-evaporated at room temperature. In the high $\mathrm{Ag}$ content region, $M_{\mathrm{s}}$ decreases with an increasing amount of $\mathrm{Ag}$, as does $M_{\mathrm{s}}{ }^{*}$. The decrease of $M_{\mathrm{s}}$ with average $\mathrm{Ag}$ content tends to be less than is expected for a homogeneous dilution effect (the slope through the datapoints is less steep). Another possible reason for the weaker decrease of $M_{\mathrm{s}}(\% \mathrm{Ag})$ is an electron sharing of $\mathrm{Co}$ and $\mathrm{Ag}$. Possibly an 'electron transfer' of Co to Ag occurs, since $\mathrm{Ag}$ is the more noble metal of the two. A similar polarization mechanism takes place in $\mathrm{Co} / \mathrm{Pd}$ multilayers. However, the electron transfer from $\mathrm{Co}$ to $\mathrm{Ag}$ is less likely than the occurrence of $\mathrm{Co}-\mathrm{Co}$ clusters and, if it should take place, then it is probably a minor effect. Furthermore, the presence of Co-rich regions is proved by NMR measurements. It is also most likely because of the compositional separation.

Another argument for the decreasc of $M_{\mathrm{s}}$ at high $\mathrm{Ag}$ at\% at room temperature is probably due to thermal relaxation in small Co clusters. Temperature dependent measurements should be carried out to clarify this point.

\section{Discussion and conclusions}

In as deposited $\mathrm{Co}-\mathrm{Ag}$ films, two separate lattices are present. At higher substrate temperatures, the lattice parameters for fcc $\mathrm{Ag}$ and fcc Co get closer to the pure metal lattice parameter. Clearly CS with regions existing of $\mathrm{Co}-\mathrm{Co}$ clus- ters and $\mathrm{Ag}-\mathrm{Ag}$ clusters, but also $\mathrm{Co}$-rich regions with some amount of $\mathrm{Ag}$ in it, are present. This has also been confirmed by NMR experiments. By preliminary NMR experiments we have shown that, for $(\mathrm{Co}-\mathrm{Cr}$ and $\mathrm{Co}-\mathrm{Ag})$ films deposited at room temperature, the number of $\mathrm{Co}-\mathrm{Co}$ clusters has increased after an annealing treatment is carried out [16,17]. After annealing, an hcp Co structure is present.

At low at $\% \mathrm{Ag}$, the $M_{\mathrm{s}}$ vs. at $\% \mathrm{Ag}$ decreases according to a 'nearly-merely' volume dilution and $M_{\mathrm{s}}^{*}$ vs. at $\% \mathrm{Ag}$ is nearly constant. $M_{\mathrm{s}}$ is not yet zero at 80 at $\% \mathrm{Ag}$.

The samples deposited at elevated substrate temperature have a slightly higher $M_{\mathrm{s}}$ than the low temperature samples and the $M_{\mathrm{s}}$ increases after an anneal step. Since the solid solubility for $\mathrm{Co}$ and $\mathrm{Ag}$ is very small, an amount of extra energy can increase the separation between them. In that case, the $\mathrm{Ag}$ in the Co matrix can diffuse to the $\mathrm{Ag}$ clusters, whereby the number of $\mathrm{Co}-\mathrm{Co}$ neighbours is increased, which is supported by also NMR experiments.

The MR effect we found in our films compares well with sputtered film in the same thickness range [15], although the maximum effect occurs at a slightly different composition. It is not clear what the role is of the different processes, causing the separation of the $\mathrm{Co}$ and $\mathrm{Ag}$. More work has to be done to obtain a better understanding of these mechanisms.

\section{References}

[1] M.N. Baibich, J.M. Broto, A. Fert, F. Nguyen Van Dau, F. Petroff, P. Etienne, G. Greuzet, A. Friederich and J. Chazelas, Phys. Rev. Lett. 61 (1988) 2472.

[2] J.A. Barnard, A. Waknis, M. Tan, E. Haftek, M.R. Parker and M.L. Watson, J. Magn. Magn. Mater. 114 (1992) 230; B. Dieny, V.S. Speriosu, S.S.P. Parkin, B.A. Gurney, D.R. Wilhoit and D. Mauri, Phys. Rev. B43 (1991) 1297.

[3] A.E. Berkowitz, J.R. Mitchell, M.J. Carey, A.P. Young, S. Zhang, F.E. Spada, F.T. Parker, A. Hutten and G. Thomas, Phys. Rev. Lett. 68 (1992) 3745.

[4] J.Q. Xiao, J.S. Jang and C.L. Chien, Phys. Rev. Lett. 68 (1992) 3749.

[5] M.L. Watson, J.A. Barnard, S. Hossain and M.R. Parker, J. Appl. Phys. 73 (1993) 5506; A. Tsoukatos, H. Wan, 
G.C. Hadjipanayis and K.M. Unruh, J. Appl. Phys. 73 (1993) 5509

[6] F.A. Pronk and J.C. Lodder, IEEE Trans. Magn. Mag-24 (1988) 1744.

[7] H. Van Kranenburg, J.C. Lodder, Y. Maeda, L. Toth and Th.A.J. Popma, IEEE Trans. Magn. MAG-26 (1990) 1620 .

[8] H. van Kranenburg, J.C. Lodder and Th.A.J. Popma, J. Magn. Magn. Mater. 120 (1993) 225.

[9] S. Keitoku, T. Kamimori and M. Goto, Jpn. J. Appl. Phys. 25 (1986) 1668.

[10] T. Motohiro, Y. Takeda, Y. Watanabe and S. Noda, in: Clusters and Cluster-assembled Materials, eds. R.S. Averback, J. Bernholc and D.L. Nelson, Mater. Res. Soc. Symp. Proc., Vol. 206 (Materials Research Society, Pittsburgh, PA, 1991) p. 423.

[11] H. van Kranenburg, J.C. Lodder, Th.A.J. Popma, K. Takei and Y. Maeda, J. Magn. Soc. Jpn. 15 Suppl. no. S2 (1991) 33
[12] H. Van Kranenburg, J.C. Lodder and Th.J.A. Popma, J. Magn. Magn. Mater, 120 (1993) 353.

[13] A.G. Dirks and H.J. Leamy, Thin Solid Films 47 (1977) 219.

[14] A.R. Miedema, Philips Techn. Rev. 33 (6) (1973) 149.

[15] J.A. Barnard, S. Hossain, M.R. Parker, A. Waknis and M.L. Watson, J. Appl. Phys. 73 (1993) 6372.

[16] H. van Kranenburg, PhD thesis, University of Twente, Oblique co-evaporated thin films for magnetic recording (1992), ISBN: 90-9005476-6.

[17] J.C. Lodder, H. van Kranenburg, K. Takei and Y. Maeda, J. Magn. Magn. Mater. 118 (1993) 248.

[18] S.H. Liou, S. Malhotra, Z.S. Shan, D.J. Sellmyer, S. Nafis, John A. Woollam, C.P. Reed, R.J. DeAngelis and G.M. Chow, J. Appl. Phys. 70 (1991) 5882.

[19] F.A. Pronk and J.C. Lodder, J. Phys. (Paris) C8 Suppl. no. 12 , Tome 49 (1988) 1991. 